\title{
Risk Profile of Weather and System-Related Port Congestion for the Cape Town Container Terminal
}

\section{Lilian Potgieter}

https://orcid.org/0000-0002-5248-4540

Stellenbosch University, South Africa

lilian.potgieter26@gmail.com

\section{Jan Havenga}

https://orcid.org/0000-0003-2844-719X

Stellenbosch University, South Africa

janh@sun.ac.za

\author{
Leila Louise Goedhals-Gerber \\ https://orcid.org/0000-0003-2924-4159 \\ Stellenbosch University, South Africa \\ Leila@sun.ac.za
}

\section{Abstract}

The South African maritime industry suffers from a number of risks, with the most prominent source of risk stemming from congestion within port terminals. The Port of Cape Town is one of South Africa's main ports. Two of the risks faced by the Cape Town Container Terminal (CTCT) and associated with port congestion are adverse weather and system challenges. The study investigated the current frequency and scheduling impact of weather- and system-related congestion experienced by ocean carriers in the CTCT. This study was conducted in two phases, namely exploratory secondary research, followed by primary research. The secondary research provided background information and historical data on the Port of Cape Town, the CTCT, and congestion in South Africa's ports as well as global port congestion. In addition, the primary data collected, which comprised personal interviews and email correspondence, were used to analyse current port congestion within the CTCT and to develop risk profiles. The major findings of this study indicate that both weather- and system-related port congestion are ranked as major risks occurring between 2011 and 2018 in the CTCT, suggesting that greater risk mitigation strategies should be implemented. This risk ranking will likely worsen in the future, if mitigation strategies are not improved. The study classifies weather- and system-related port congestion in the CTCT in terms of the level of risk and helps identify which areas management should focus on to mitigate greater levels of risk in the future.

Keywords: Cape Town Container Terminal; port congestion; risk; system delays; weather delays

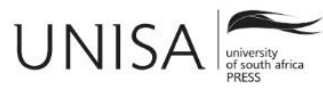




\section{Introduction}

Maritime ports as a source of risk have been an area of interest to those individuals and organisations reliant on ports for trade purposes, either internationally or coastally. The most prominent source of risk, particularly in the case of South Africa, results from port congestion (Richer 2010, 12). In the case of the Port of Cape Town and its container terminal, adverse weather conditions and system challenges are the central causes of congestion. This places pressure on port management and can cause inefficiencies in both port operations and the operations of international shipping companies.

Unlike capacity, productivity and port security, the risk management process does not place much importance on the risk of port congestion (Davids 2015; Mokhtari and Ren 2014). It is deemed a regular occurrence rather than a risk, which could potentially be reduced (Davids 2015; Gidado 2015). Risk management is not yet viewed holistically in the marine and maritime industry (Mokhtari and Ren 2014). However, the importance of the Port of Cape Town as a multi-cargo port servicing South Africa and West Africa, highlights the importance of effectively managing port congestion risk over the long term.

The adverse weather conditions frequently experienced in the Port of Cape Town include high wind speeds, thick fog and large swells. These conditions are usually dominant during summer (December to February) and winter (June to August) months. However, as weather patterns are relatively unpredictable, one cannot plan based on this presumption, thus making congestion relatively difficult to manage. System delays are similarly unpredictable, as bottlenecks in the current Terminal Operating System (TOS) and power outages can cause unforeseen delays and result in system downtime. This paper centres on addressing the risk associated with weather- and system-related port congestion within the Cape Town Container Terminal (CTCT). The objectives of the study focus on developing a basic risk profile of weather- and system-related port congestion in the CTCT for the purpose of assigning a specific risk ranking to the risk.

The risk profile is developed through the investigation of current weather and system delays, specifically with regard to the frequency of delays and the time impact of delays. The overall purpose of the profile is to emphasise the importance of managing port congestion and to identify implications and recommendations for Transnet and relevant shipping companies.

\section{Literature Review}

The literature review introduces some of the concepts relating to the study, namely: the risk concept; maritime ports and port-related risks; previous research on global port congestion; the Cape Town Container Terminal; port congestion risk; and weather- and system-related port congestion. 


\section{The Risk Concept}

Risk is often perceived as either a potential threat or a potential opportunity for gain (Young 2014, 2). The loss-versus-gain perspective of risk points to the opportunity of either minimising the risk or achieving some benefit from the risk, according to Young $(2014,2)$. Both perspectives involve a level of uncertainty, with high uncertainty resulting in higher risk and less uncertainty resulting in lower risk.

According to Brindley $(2004,7)$, and supported by Uusitalo et al. (2015), uncertainty can be defined as the lack of information pertaining to a decision situation and the need for judgement in evaluating the impact and probability of the situation. This infers that in extreme circumstances, uncertainty could be defined as situations where the risk and its likelihood are unknown and, therefore, cannot be measured. There is, however, a significant difference between uncertainty and risk (Tversky and Fox 1995). This difference is the principle that all risk events involve a conscious level of uncertainty that may result in a worthwhile reward, but at the same time expose the business to a potential loss (Potgieter 2016).

This explanation of uncertainty leads to Young's definition of risk, which states that risk can be defined as an event of uncertainty resulting in a loss or a positive outcome (Young 2014, 2). Purdy $(2010,882)$ similarly defines risk as the consequences that firms face in an uncertain environment when pursuing goals. The definition of risk adopted for this study is: the consequences and benefits that organisations encounter when making business decisions within an environment of uncertainty.

\section{Maritime Ports and Port-Related Risks}

The most important function of maritime ports is the facilitation of trade between international markets and domestic markets for the economic growth of hinterlands and/or countries (AFDB 2010). The successful functioning of maritime ports contributes to the economic wealth of a country, which leads to an overall increase in the standard of living (Janse van Rensburg 1997, 36).

Maritime ports form an important part of a supply chain, as ports can potentially influence operating costs, profitability and responsiveness to consumer demand (Lun, Lai, and Cheng 2010, 205). In addition, maritime ports are an essential part of the global transport infrastructure, as ports act as nodes in logistics chains linking inland transport modes with international trade. Furthermore, ports and port activities represent a significant portion of total supply chain costs (Panayides and Song 2009).

Research highlights the importance of maritime ports and the terminal operations within ports (Jeevana et al. 2015; Rodrigue and Slack 2017). One such terminal operation that has experienced exponential growth recently is container terminals (Fan, Wilson, and Dahl 2010, 1121). During the transportation of containerised goods, container terminals act in a similar way to ports, i.e. as nodes linking maritime trade to inland transport (Lun 
et al. 2010, 219). According to Chadwin, Pope, and Talley (1990, 19), this linkage between nodes highlights the importance of container terminals to an intermodal transportation network.

This role of container terminals acting as nodes has evolved from simple cargo handling to distribution centres with infrastructure serving as transportation hubs. Container terminals serve as the interface connecting key players in sea and land transportation, and the overall international container supply chain (Choo, Klabjan, and Simchi-Levi 2010, 98). In addition, port activities are required to fit integrally into logistics chains. Therefore, it is important to identify potential measures that can be implemented by port management to minimise the impact and frequency of port-related supply chain disruption (PSCD).

According to Loh and Thai $(2014,98)$, PSCD threats can be defined as operational risks commonly found in port operations, which are capable of disrupting the upstream and downstream flow of supply chains. The significance of ports to international trade increases vulnerability, as PSCD threats can generate a ripple effect on the network of supply chains working through ports. According to Loh and Thai (2014, 97-98), this vulnerability of ports should be addressed to ensure the functionality of port operations and to enhance overall supply chain resilience.

Port-related risks can stem from a number of sources, including a lack of or poorly maintained infrastructure/equipment capacity, low productivity, severe weather conditions and congestion (Richer 2010, 23-24). The main consequence stemming from a lack of infrastructure/equipment capacity and severe weather conditions is congestion in the container terminal and the subsequent inability of the port to accept as many containers as it should. Low productivity in a port can stem from a lack of appropriate handling equipment, outdated systems, poor management, a lack of trained crane operators, or severe weather conditions causing the shutdown of certain terminal equipment. Productivity is one of the more difficult factors to control due to the human factor involved. The two less-controllable port-related risks, which are inherently linked, are port congestion and weather conditions. Both port congestion and weather conditions can cause inefficiencies in operations - often in the form of major delays to shipments and can subsequently result in large financial losses if not taken into account during the risk management process.

\section{Previous Research on Global Port Congestion}

Port congestion is a global problem and has led to a need for research in various parts of the world. Port congestion results from various causes and is affected by a port's location. The rest of this section summarises previous studies regarding port congestion and its causes in other parts of the world.

Constructing a new oil terminal in the Port of Punta Arenas in the Republic of Chile required in-depth research on the weather-related congestion risks that are prominent in 
the region. Similar to the CTCT referred to in this study, wind speed, fog and large swells all contribute to congestion in Punta Arenas, but added to these conditions are snow and ice (Stanivuk and Tokíc 2012). The researchers found that constructing extra terminals at the port would not improve its congestion problems, as the port's availability is mostly determined by the weather in Punta Arenas.

The Canadian west coast is one of the main gateways that connects North America to Asia. This is largely attributed to geographical and strategic reasons. In recent years, the ports on the west coast experienced an increasing number of disputes resulting from port congestion. This congestion sprouts from the country's significantly increased global trading activities ( $\mathrm{Ke}, \mathrm{Li}$, and Hipel 2012).

Athanasatos, Michaelides, and Papadakis (2014) investigated the effect of extreme weather conditions on the productivity of the Port of Limassol, which is the largest port on the island of Cyprus in the Mediterranean. They discovered that various weather factors hindered its productivity. These factors include wind, rain, fog and excessive heat. Furthermore, Naude (2016) conducted a case study on the Port of Paranagua in Brazil, which experienced significant congestion on the vessel side. This meant that ships cued up outside of the port because of excessive loading periods. These extensive periods resulted from a lack of infrastructure and poor systems.

\section{Cape Town Container Terminal}

Figure 1 shows the container volumes moving through the CTCT from 2011 to 2018. The figures indicate that containerised trade through the Port of Cape Town was relatively low in 2011, which was followed by an increase over the following five years. Cape Town's container content is in general mainly agriculture related. Thus, 2011's low volumes are linked to a combination of the after effect of the global recession on other commodities and a low-fruit season (Van Eeden 2019). The CTCT was severely impacted by poor weather conditions, for example ocean swells, strong under water currents, high wind speeds and thick fog during 2017 and 2018 (Davids 2015; Transnet Port Terminals 2018). This resulted in some customers opting to bypass the terminal, which culminated in the terminal's volumes falling (Transnet Port Terminals 2018). 
Potgieter, Goedhals-Gerber and Havenga

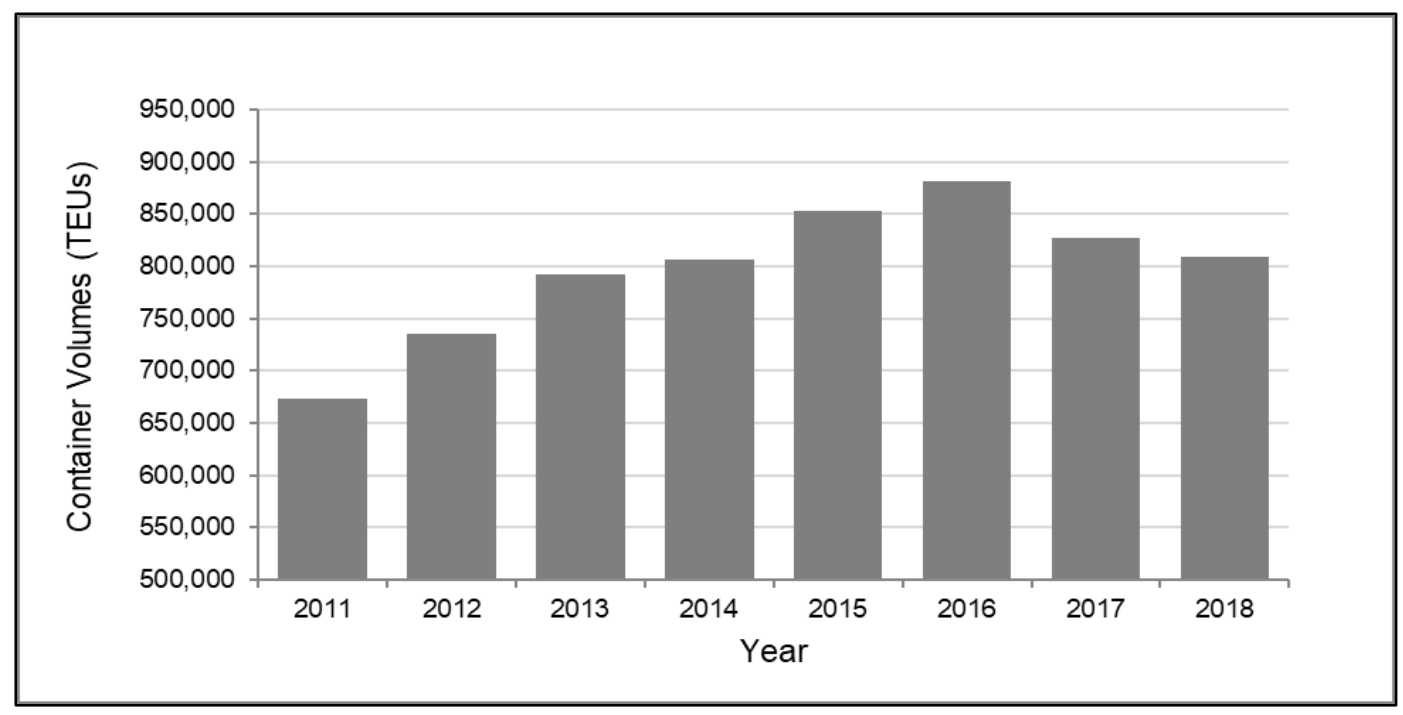

Figure 1: Port of Cape Town container volumes, 2011-2018

Source: Transnet Port Terminals, 2019

The Port of Cape Town experiences severe weather conditions and system challenges, which influence the operational efficiency of the container terminal (Davids 2015). This impacts on safety within the port, terminal operational efficiency and vessel congestion. These weather and system challenges have, according to Davids (2015) from Transnet Port Terminals (TPT), become part of the regular working conditions in the terminal and are considered an increasing risk to port efficiency by TPT.

With the increase in containerisation internationally, container terminals have had to improve their efficiency to remain competitive (Stander 2014). The Port of Cape Town is one of South Africa's main ports and plays an important role in South Africa's economy. The risks of adverse weather conditions and system challenges faced by the CTCT, place increasing pressure on port management and highlight the importance of effectively managing port congestion risk over the long run.

\section{Port Congestion Risk}

Maritime ports are widely considered as critical logistics points in transportation and international trade. However, a common problem experienced by ports around the world is congestion resulting from various factors; the CTCT is no different, given the discussion above. These factors include a lack of infrastructure and equipment capacity, a lack of productivity, and adverse weather conditions (Meersman, Van de Voorde, and Vanelslander 2012, 49). The occurrence of port congestion is a global supply chain issue, as it not only impacts on larger maritime ports, but also on smaller ports worldwide. 
According to Veloqui et al. (2014, 615-616), the continuous growth of maritime transport since 2011 has resulted in an increase in congestion in maritime ports, which has consequently made congestion a common problem worldwide. In addition, the growth in container trade worsens congestion (Fan et al. 2012, 1121). The most significant impact of port congestion relates to port competition. Maritime ports operate within a "wide-open" marketplace. This infers that ports must deal with a large amount of competitiveness as shippers can choose from numerous available ports and logistics paths, which best suit changing customer requirements.

According to Meersman et al. (2012, 49), congestion appears in two forms. Congestion can be relatively hidden and appear as congestion costs, or it can visually appear in the form of vessel or vehicle queuing. A more common means of classifying port congestion is by the area from which it stems. According to De Wet (2014, 65-67), port congestion primarily takes place in two areas of a port, namely the maritime side and the landside. Maritime-side congestion impacts the movement of vessels and is generally caused by severe weather conditions, while landside congestion impacts the movement of vehicles and is commonly caused by traffic congestion in and around ports.

\section{Weather- and System-related Port Congestion}

Port congestion, as mentioned previously, generally occurs because of adverse weather conditions and system delays, which cause vessel and vehicle congestion. Adverse weather conditions common to the Port of Cape Town include large ocean swells, strong underwater currents, high wind speeds and thick fog. These weather conditions are natural to Cape Town as a result of the city's geographical location. Situated in an area known as the Cape of Storms, the Port of Cape Town commonly experiences severe weather during summer (December to February) and winter (June to August) months of the year, which subsequently limits the ability of the port and results in congestion (Birkenstock 2015). Safe entry into the port and its terminals is often prevented by large swells and high wind speeds. This subsequently results in delays as the vessels drift outside the port. In addition, high wind speeds can cause further delays as certain terminal equipment (cranes and gantries) cannot be operated safely in conditions of over 80/100kph wind speeds.

In the winter months (June to late August) Cape Town often suffers from severe storms linked to cold fronts and low-pressure systems. These low-pressure systems result in surface winds, which can reach maximum speeds of $100 \mathrm{~km} / \mathrm{h}$ (City of Cape Town 2014). According to the Beaufort Wind Scale (2015), this can result in structural damage and large ocean swells. Average wind speeds during winter months are, however, significantly lower (between 13.3 and $15.5 \mathrm{~km} / \mathrm{h}$ ), signifying that severe storms occur irregularly throughout the season (Cape Town Weather Statistics 2014).

The Cape Town area also experiences severe wind conditions in the summer months (December to February). These gale-force winds can last several consecutive days and are known to residents as the "Cape Doctor" (City of Cape Town 2014). Similar to the 
winter winds, the "Cape Doctor" can reach gale force strength or a Beaufort wind scale of nine or ten (Beaufort Wind Scale 2015).

To deal with the adverse weather conditions experienced at the Port of Cape Town, all heavy-duty equipment such as cranes, gantries and carriers are equipped with an anemometer. This device is designed to measure wind direction and wind speed. When winds exceed $80-100 \mathrm{kph}$, increasing the danger of equipment operation, the device sends warning signals to the crane operator. The operator can then decide whether to continue operating, with the hope that wind speeds will decrease, or discontinue equipment operation. If the operator chooses to continue working, and wind speeds increase, the device will send a final signal to the crane system resulting in automatic shutdown of the equipment until wind speeds decrease. In addition, certain gantries and cranes have a vibration plate built into the equipment. This plate vibrates in the wind and will send warning signals to the operator when wind speeds increase past unsafe levels of between $80-100 \mathrm{kph}$. These different safety mechanisms are vital in preventing accidents in the terminal; however, they are also contributing factors to port congestion.

Most cranes and gantries in the CTCT cannot operate if wind speeds exceed a certain speed. Generally, straddle carriers can operate in wind speeds of up to $85 \mathrm{~km} / \mathrm{h}$, while gantry cranes can operate in wind speeds of up to $100 \mathrm{~km} / \mathrm{h}$. However, when winds surpass these speeds, the loading and unloading of berthed vessels and container stacks are impacted. Currently, the CTCT handles between 14 and 15 containers per crane per hour. The TPT's target is 20 container moves per crane per hour; however, this is still below the international benchmark of 25 container moves per crane per hour. This less than optimal efficiency is mainly due to high wind speeds resulting in the shutdown of equipment. A further hindrance to terminal operations is thick fog. Although less common than high wind speeds, thick fog reduces visibility, which reduces equipment operation safety and accuracy.

In addition to the weather-related challenges discussed, the landside of the Port of Cape Town must deal with system and/or equipment related challenges. System delays refer to time delays resulting from the current TOS in use in the CTCT, i.e. the NAVIS SPARCS N4 system. NAVIS system-related issues include shutdowns, maintenance and power failures (including load shedding), which have a negative impact on congestion levels in the CTCT. The most noticeable impact involves increased turnaround time of vehicles within the terminal, as vehicles wait to be allowed access to the stacks for loading and unloading of containers.

\section{Methodology}

The study made use of a deductive, mixed-methods research approach. A mixedmethods approach refers to the use of a combination of qualitative and quantitative data. The mixed-methods approach applied was of a sequential, multi-phase nature, because qualitative data were collected prior to quantitative data, which was followed by the collection of additional qualitative information to explain the quantitative data. A 
deductive approach is seen as a theoretical framework where literature is used to understand and identify certain theories that will be tested against the data obtained (Saunders, Lewis, and Thornhill 2016). Primary research was required for this study due to the lack of prior research conducted on risk and port congestion in a South African context. In addition to the lack of literature, this study required secondary data pertaining to the impact (measured in number of hours delayed) and frequency (of delays) of port congestion, which could only be acquired from those directly influenced by congestion, namely, Transnet National Ports Authority (TNPA), TPT and various shipping companies. Data were collected from the three sources to gain insight on the required input from both the shipping perspective and the port perspective. Data were collected from both TNPA and TPT to obtain a broader port view and more specific container-related data. The primary and secondary research was conducted using "methodological triangulation" techniques. Triangulation refers to using more than one method to collect data on the same topic. It helps to assure the validity of research by making use of an assortment of methods to collect data on the same topic. This includes different types of samples and methods of data collection (Research Gate 2019). The research made use of both qualitative data in the form of interviews, and quantitative data in the form of Excel spread sheets for the triangulation of the data.

The population used for the study was Transnet (Port) and shipping companies working through the Port of Cape Town. The population was used to collect the primary as well as the secondary data. Due to the limited availability of study participants and the narrow scope of the study, a non-probability sampling design was selected. As this study examined both the port perspective and the shipping perspective of port congestion, both viewpoints required adequate representation in the sample. Therefore, a combination of different non-probability sampling techniques was used. The combination of techniques used includes judgement sampling, convenience sampling, and snowball sampling. These techniques were used simultaneously to identify study participates who met the appropriate criteria and were willing and able to assist. The participants included TNPA, TPT and shipping line representatives. It was determined that all three perspectives would be included to offer a more holistic view of port congestion and ensure credibility of the qualitative data that were collected through semi-structured interviews through the triangulation of sources, i.e. TNPA, TPT and shipping representatives.

The qualitative portion of the primary research included seven personal, semi-structured interviews and two email-facilitated interviews. Four of the nine interviews were conducted with shipping companies and the remaining five interviews were conducted with representatives from the port (two with TNPA and three with TPT). To ensure dependability, the interviews and email correspondence comprised a semi-structured interview template, which guided the researchers when interviewing the participants and assisted in uncovering re-occurring and on-going themes, including the concept of risk within ports, the risk within international trade, the role of ports, and port congestion. The data obtained from these semi-structured interviews and threads of 
email correspondence were analysed, categorised and reported using the thematicanalysis method. The themes revealed were then categorised into risk concept; port information; port congestion; and additional news-related information. These themes, along with the quantitative data collected and the prior secondary research, were used to develop a base risk profile for current port congestion within the CTCT.

In addition to the qualitative data collected from the semi-structured interviews and email correspondence, quantitative data from secondary sources were used to determine the scheduling impact and frequency of weather- and system-related port congestion. This comprised time series Excel data sheets from the study participants pertaining to weather delays and system delays. This data were analysed using graphical statistics such as line charts, frequency bar charts, scheduling impact bar charts, and risk maps.

The frequency of port congestion can be measured in several ways. For the purpose of this study the frequency of port congestion was taken to refer to the number of observations (in percentage format) exceeding the trend line of the data. These percentages of incidences per year were considered relative to the average of all the years featured in the data series and were thus only an indication of the frequency of port congestion incidences. The method described above was, however, the most appropriate, given the data collected. For the analysis of the scheduling impact of port congestion, descriptive techniques were used, where common responses from interviewees were used to determine the amount of additional time or delays experienced by ocean carriers due to weather and system delays. The frequency and scheduling impact of port congestion were analysed using both numerical and graphical descriptive statistics. However, before frequency and scheduling impact could be analysed, the individual data sets collected were analysed. All graphical and numerical statistics computed for the different data sets were done using Microsoft Excel.

This relatively small sample size of nine (seven personal, semi-structured interviews and two threads of email correspondence) means that these results cannot be inferred to other ports. However, while the findings may not be applicable to other container terminals, the overall methodology behind the developed risk profiles can be applied to other South African ports, which similarly suffer from the risk of port congestion, and therefore support the dependability of the research. The confirmability of the research is ensured by the fact that the findings are based on participants' responses and linked to theory published on the field of research.

For the risk portion of this study, port congestion was measured using two measurements, namely risk frequency, and risk impact. These measures, according to Griffiths (2007), should be used to calculate the risk severity of port congestion.

The formula for the risk severity calculation is as follows (Griffiths 2007): 
This risk severity was consequently interpreted using specific coding systems for the two data sets analysed. The development of the individual coding systems involved three components, namely, the code itself (1-5), the interpretation of the code, and the interval ranges allocated to the individual codes. It was decided that a single coding system should be used for the frequency component of risk - as this element was measured as a percentage for all the data sets. The impact component of risk, however, required the development of two separate coding systems for the two data sets analysed, as each was measured differently and used different interval ranges (Griffiths 2007).

Table 1 details the coding system used for the frequency component of port congestion seen in the two data sets, while Table 2 details the coding systems used for the time impact (scheduling impact) component of port congestion. The coding systems created for the two data sets were based on the input of industry experts, obtained from interviews conducted with shipping companies (Maersk and MSC) and Transnet, and drew on experts' perceived severity of delays. In addition to the input received from interviews with industry experts, their insight was combined with knowledge acquired through the literature review. Overall, these two coding systems were used to interpret the severity of weather- and system-related port congestion as a risk to ocean carriers.

Table 1: Coding system used for frequency

\begin{tabular}{|l|l|l|}
\hline Interpretation of Code & Coding & Frequency percentage \\
\hline Rare & 1 & $0-20 \%$ \\
\hline Infrequent & 2 & $21-40 \%$ \\
\hline Fairly frequent & 3 & $41-60 \%$ \\
\hline Frequent & 4 & $61-80 \%$ \\
\hline Extremely Frequent & 5 & $81-100 \%$ \\
\hline
\end{tabular}

Table 2: Coding system used for time impact (additional time)

\begin{tabular}{|l|l|l|l|}
\hline $\begin{array}{l}\text { Interpretation of } \\
\text { Code }\end{array}$ & Coding & Weather Delays & System Delays \\
\hline Insignificant & 1 & $0-1$ hour & $0-0.2$ hours \\
\hline Minor & 2 & $1.1-2$ hours & $0.21-0.4$ hours \\
\hline Moderate & 3 & $2.1-3$ hours & $0.41-0.6$ hours \\
\hline Major & 4 & $3.1-4$ hours & $0.61-0.8$ hours \\
\hline Critical & 5 & More than 4 hours & More than 0.8 hours \\
\hline
\end{tabular}

The risk severity calculations were subsequently used to develop risk "heat-maps" to determine the level of risk that weather- and system-related port congestion currently poses. For the development of the "heat-maps" the risk severity calculations were interpreted using a coding system. This interpretation is shown in Figure 2: where $1=$ minor risk (green); $2=$ moderate risk (yellow); $3=$ major risk (orange); and $4=$ critical risk (red). 
Potgieter, Goedhals-Gerber and Havenga

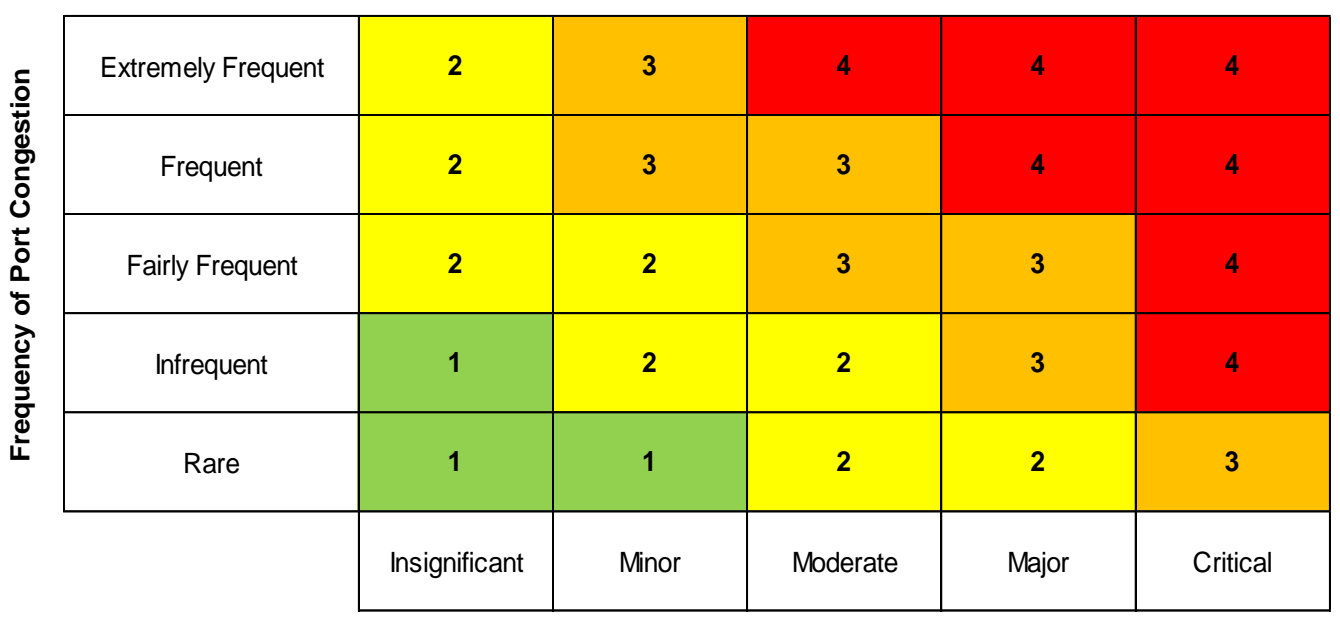

Time Impact of Port Congestion

Figure 2: Risk "heat-map" ranking system for port congestion

Source: Created by authors for the purpose of this study; adapted from Supply Chain Risk Leadership Council, August 2011

The results of the "heat-maps" were subsequently consolidated into a table, which was used to calculate the overall risk rating to be assigned to weather- and system-related port congestion as a whole per year. The results of the study are detailed in the following section.

\section{Results}

The results of this study relate to the current weather- and system-related port congestion experienced in the Port of Cape Town.

\section{Current Weather-related Port Congestion}

The weather delays are plotted on a time series line chart, as seen in Figure 3. The linear trend line shown on the chart indicates that a slight downward trend exists in the data. This is not particularly significant as weather patterns vary over time and often do not exhibit significant trends in a relatively short-term analysis, as is provided below (Nel 2015). 


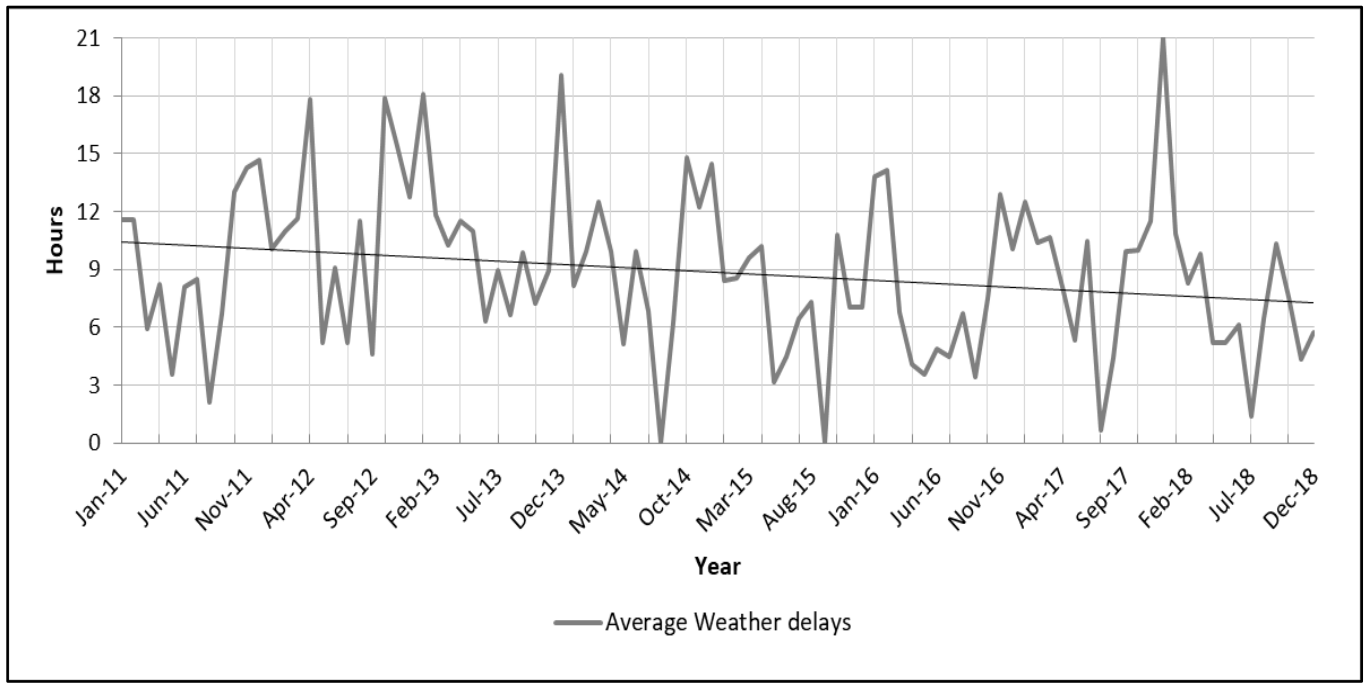

Figure 3: Weather delays recorded within the CTCT (2011-2018)

In addition, the line chart exhibits a number of increases in the delays resulting in peaks, which are likely due to periods of exceptionally severe weather conditions. Similarly, the significant decreases and troughs could be attributed to times of mild weather. Weather delays were analysed further to take into account conditions experienced in the winter months versus the summer months. Winter months generally include June, July and August, while summer months range from early December to late February. Figure 4 illustrates the weather delays recorded during the winter and summer seasons of 2011 to 2018.Figure 4 shows that weather delays experienced during summer are significantly more than those experienced in winter. Summer delays were recorded to have an average of 11.83 hours, which is significantly higher than the average of 6.12 hours recorded for the winter season. The strong winds experienced during the summer months, have a larger impact on terminal operations than the winds faced during the winter months. Generally, during summer, the wind is diverted across False Bay into the Table Mountain range where it increases in velocity by 2.5 times before exiting and hitting the Port of Cape Town. This significantly reduces equipment operating hours as wind speeds often exceed the recommended speeds for safe operations (McEwan 2015). 


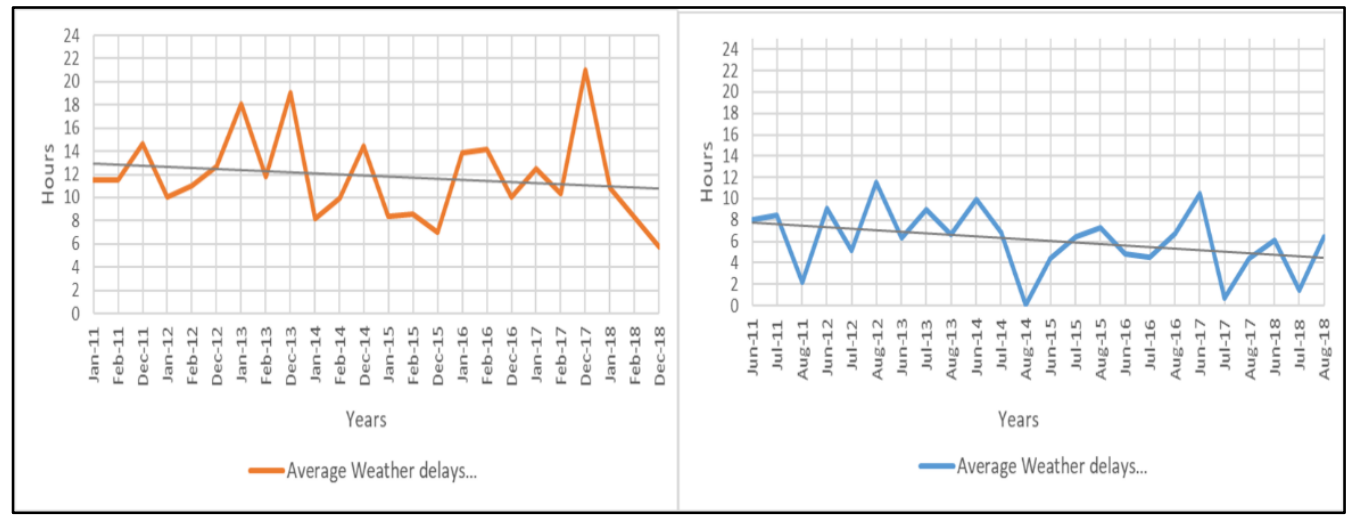

Figure 4: Weather delays recorded in summer and winter months (2011-2018)

In addition to the line charts, the frequency of weather-related congestion was analysed. The bar chart in Figure 5 illustrates that weather delays have fluctuated between 2011 and 2018. In 2011 weather delays amounted to $25 \%$ of the total time spent in CTCT that year. This increased to $33.33 \%$ in 2012 , which was followed by a decrease to $16.67 \%$ in 2013, while 2014 saw another increase to 33.33\%. In 2015, ocean carriers experienced weather-related congestion $11.69 \%$ of the time that they spent inside the CTCT that year, however, this increased to 25\% in 2016. The years 2017 and 2018 saw another decrease in weather-related congestion to $16.67 \%$ and $17.01 \%$ respectively.

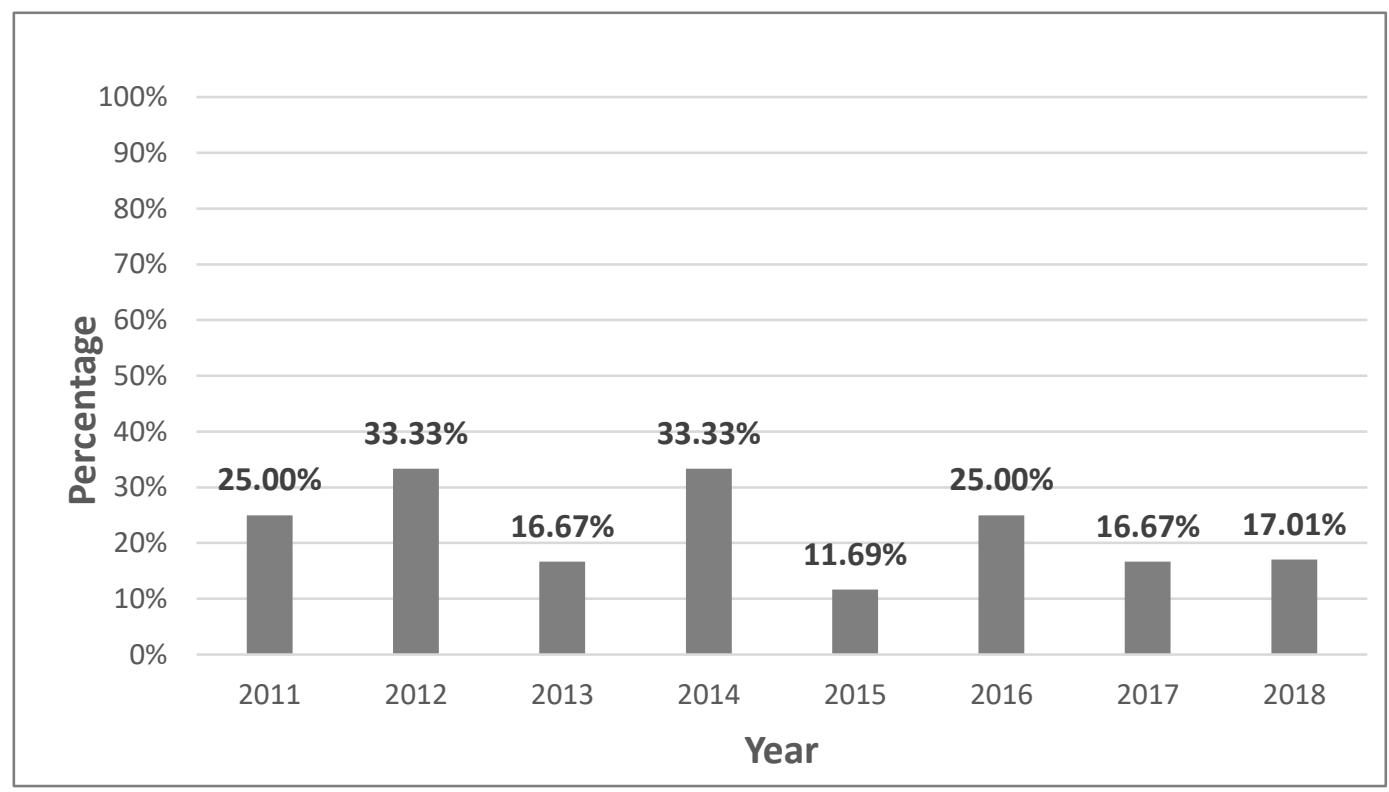

Figure 5: Percentage of weather-related port congestion (2011-2018) 
The fluctuations seen in Figure 5 are most likely due to the degree of variability found within the data set (coefficient of variation of $47 \%$ ) and the unpredictable nature of weather conditions in the Port of Cape Town (Davids 2018; Nel 2015). The fluctuations do, however, correlate with the slight downward trend exhibited in the line chart (Figure $3)$.

The scheduling impact of weather-related congestion was analysed in a similar manner to the frequency of congestion. The impact of weather delays was defined as the additional time experienced due to weather related congestion -in other words, the amount of time exceeding the average. All observations exceeding the average were considered congestion. Figure 6 indicates the total weather delays experienced by ocean carriers from 2011 to 2018.

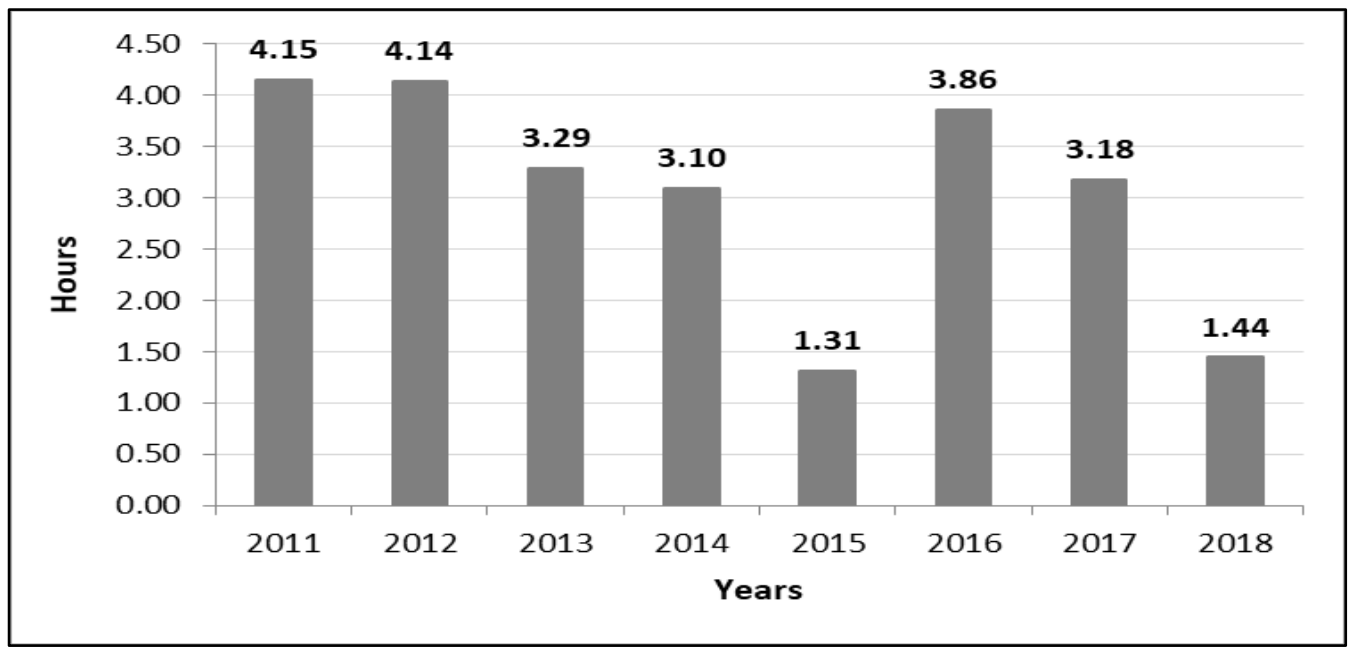

Figure 6: Weather delays experienced within the CTCT (2011-2018)

Figure 6 indicates that in 2011, total weather delays amounted to 4.15 hours more than the average delay of 8.9 hours. This remained more-or-less constant in 2012 at 4.14 hours, and decreased slightly to 3.29 hours and 3.10 hours respectively in 2013 and 2014. These peaks were, however, followed by a decrease to 1.31 hours in 2015 and then an increase to 3.86 hours in 2016 . The year 2017 saw the scheduling impact remain constant at 3.18 hours, before decreasing again to 1.44 hours in 2018. Figure 6 therefore suggests that the impact of weather delays (in hours) is relatively constant (approximately 3.67), despite the occasional dip every few years.

\section{Current System-related Port Congestion}

System delays, according to TNPA (Birkenstock 2015), refer to time delays resulting from NAVIS system-related issues such as shutdowns, maintenance and power failures. The NAVIS system is a web-based terminal operating system developed to govern the movement of all container logistics and operations. It offers cargo-related information 
from the point of entry at the terminal, through the stacks and to the loading of the vessel (Stander 2014).

System delays are plotted on a line chart, as seen in Figure 7, which includes a linear trend line. The trend line indicates that a slight upward trend exists in system delays.

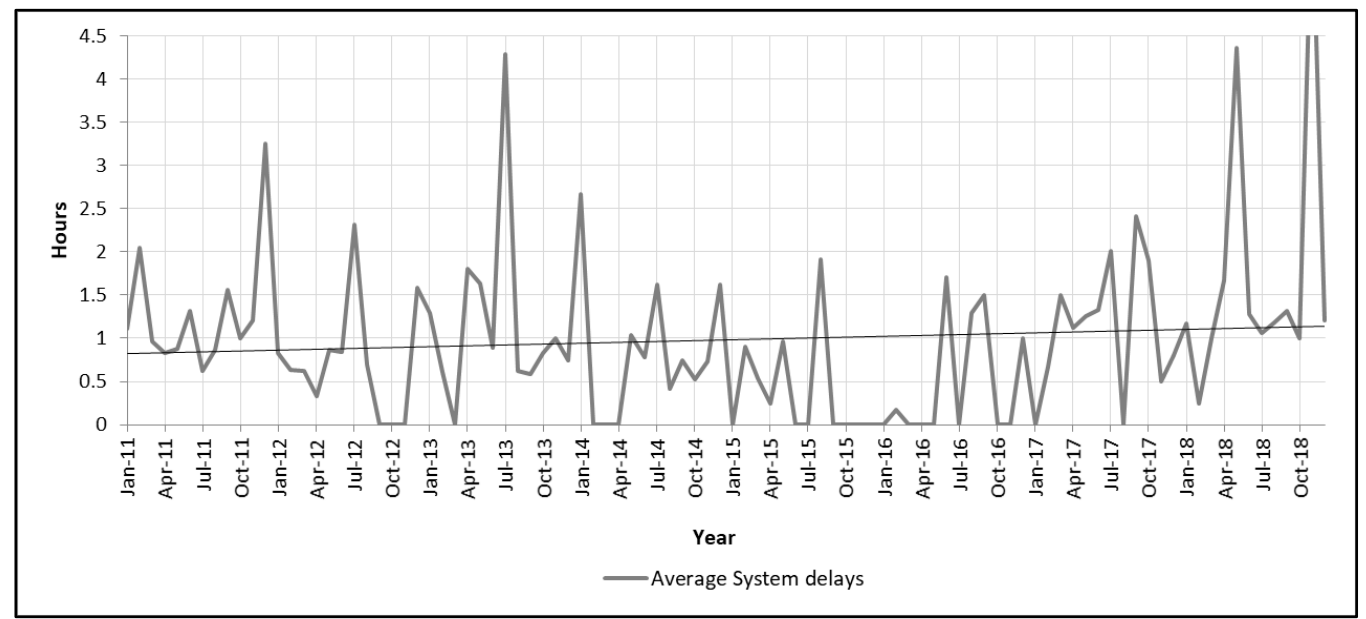

Figure 7: System delays recorded within the CTCT (2011-2018)

This suggests that there was a slight increase in system delays over the eight-year period. The fluctuation in delays in the earlier years may be due to the implementation of a NAVIS system upgrade in 2012, which required operations staff to obtain additional training (Davids 2015). The frequency of system delays was analysed in addition to the line chart using a bar chart to determine the percentage of delays experienced by ocean carriers from 2011 to 2018.

Figure 8 shows that occurrences of system delays within the CTCT decreased from $41.67 \%$, that is, ocean carriers experienced congestion due to system delays $41.67 \%$ of the time that they spent in the CTCT in 2011 to $16.67 \%$ in 2012. This sudden decrease is likely due to the implementation of new technology on the reefer (or refrigerated container) stacks, which subsequently decreased the number of system-related delays (Port of Cape Town 2015), but likely resulted in coordination challenges for TPT (Marais 2015). The reefer stacks are where the refrigerated containers are plugged into a power source while inside the CTCT. System delays, however, saw a large increase in 2018 to $83.33 \%$ due to multiple incidents of power outages, which resulted in system failures (Transnet Port Terminals 2019). 
Potgieter, Goedhals-Gerber and Havenga

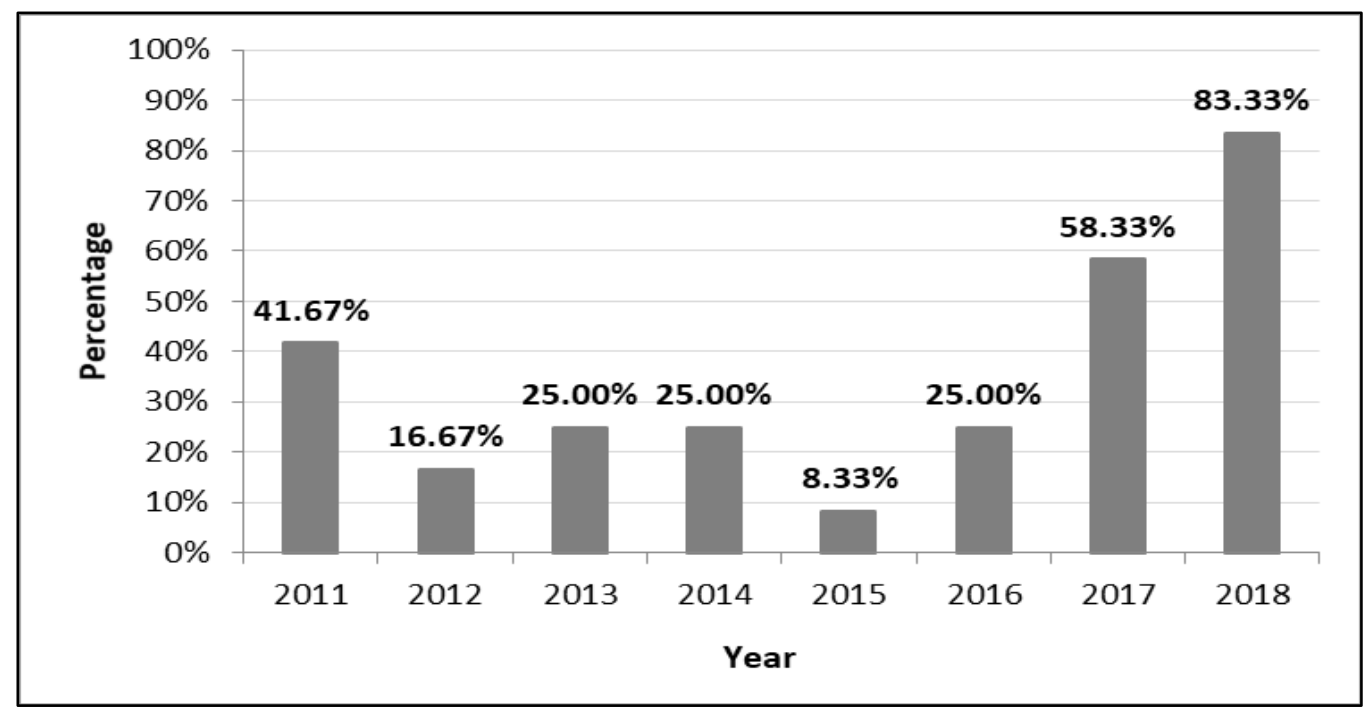

Figure 8: Percentage of system-related incidents of congestion (2011-2018)

With regards to scheduling impact, the system delays data were analysed further using a bar chart (Figure 9) to determine the amount of additional time experienced by ocean carriers due to system-related congestion. Figure 9 illustrates that in 2011 vessels experienced system delays of 0.66 hours. This, however, increased in 2012 and 2013 to 0.97 hours and 1.02 hours, respectively. In 2014, this decreased to a 0.76 -hour delay. System delays increased again in 2015 to 0.94 hours before experiencing another decrease in 2016 to 0.39 hours. Recently, system delays have shown a steady increase from 2016, to 0.67 hours in 2017 and 0.96 hours in 2018. Figures 8 and 9 highlight the fact that in 2012 and 2015, although there were relatively few system delays in terms of the number of delays that occurred inside the CTCT, the delays that did occur were quite long and therefore still have a negative impact on the CTCT. 
Potgieter, Goedhals-Gerber and Havenga

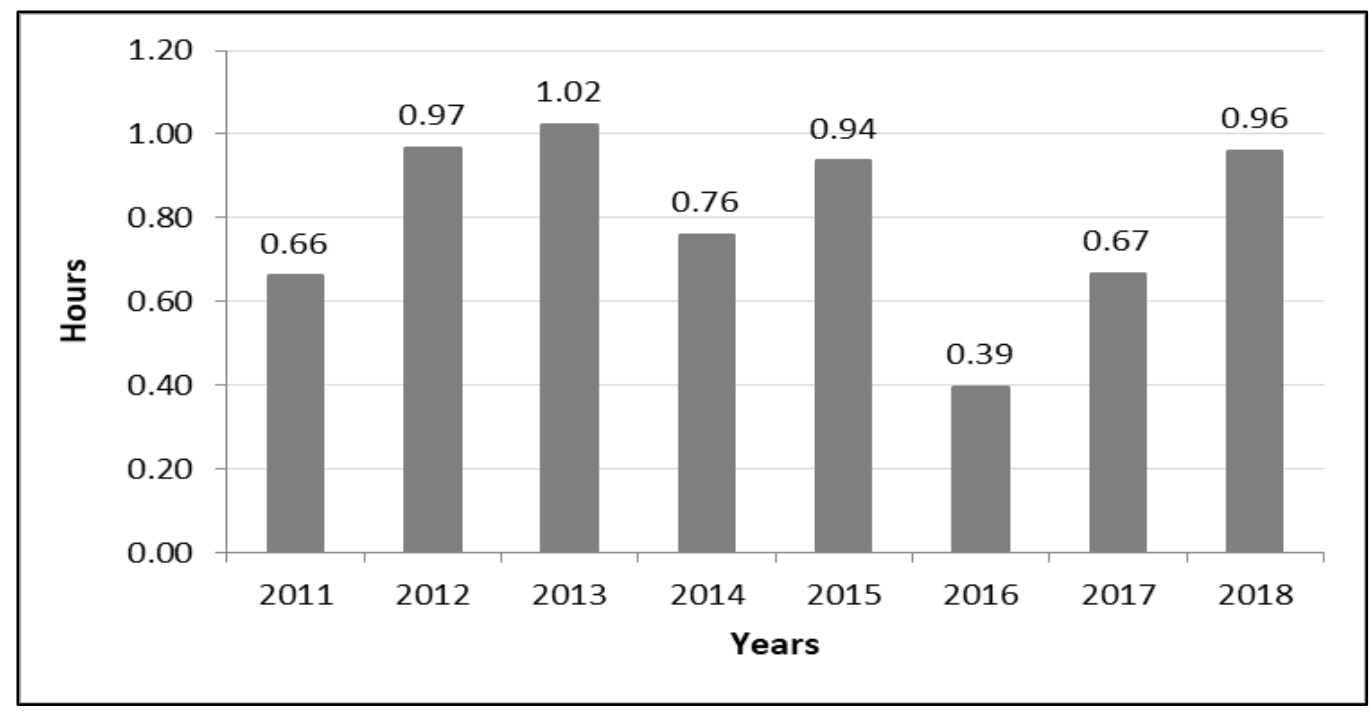

Figure 9: System delays experienced within the CTCT (2011-2018)

Figure 9 further suggests that, on average, ocean carriers experience system delays of 0.8 hours between 2011 and 2018 .

\section{Risk Profile of Port Congestion}

The analysis of weather and system delays within the CTCT was subsequently used to develop a risk profile of current weather- and system-related congestion. This was done through the use of risk severity calculations and risk "heat-maps" as mentioned in the methodology section of this article. Table 3 and Table 4 illustrate the risk severity calculations of current weather and system delays experienced by ocean carriers.

Table 3: Risk severity calculations of weather delays within the CTCT

\begin{tabular}{|l|c|c|c|c|c|c|c|c|}
\hline & \multicolumn{7}{|c|}{ Weather Delays } \\
\hline Year & $\mathbf{2 0 1 1}$ & $\mathbf{2 0 1 2}$ & $\mathbf{2 0 1 3}$ & $\mathbf{2 0 1 4}$ & $\mathbf{2 0 1 5}$ & $\mathbf{2 0 1 6}$ & $\mathbf{2 0 1 7}$ & $\mathbf{2 0 1 8}$ \\
\hline Frequency \% & $25 \%$ & $33 \%$ & $17 \%$ & $33 \%$ & $0 \%$ & $25 \%$ & $17 \%$ & $0 \%$ \\
\hline $\begin{array}{l}\text { Impact } \\
\text { (hours) }\end{array}$ & 4.15 & 4.14 & 3.29 & 3.10 & 1.31 & 3.86 & 3.18 & 1.44 \\
\hline $\begin{array}{l}\text { Risk Severity } \\
\text { (hours) }\end{array}$ & $\mathbf{1 . 0 4}$ & $\mathbf{1 . 3 8}$ & $\mathbf{0 . 5 5}$ & $\mathbf{1 . 0 3}$ & $\mathbf{0 . 0 0}$ & $\mathbf{0 . 9 6}$ & $\mathbf{0 . 5 3}$ & $\mathbf{0 . 0 0}$ \\
\hline $\begin{array}{l}\text { Average Risk } \\
\text { Severity }\end{array}$ & & & $\mathbf{0 . 6 9}$ hours & & \\
\hline
\end{tabular}


Potgieter, Goedhals-Gerber and Havenga

Table 4: Risk severity calculations of system delays within the CTCT

\begin{tabular}{|l|c|c|c|c|c|c|c|c|}
\hline & \multicolumn{7}{|c|}{ System Delays } \\
\hline Year & $\mathbf{2 0 1 1}$ & $\mathbf{2 0 1 2}$ & $\mathbf{2 0 1 3}$ & $\mathbf{2 0 1 4}$ & $\mathbf{2 0 1 5}$ & $\mathbf{2 0 1 6}$ & $\mathbf{2 0 1 7}$ & $\mathbf{2 0 1 8}$ \\
\hline Frequency \% & $42 \%$ & $17 \%$ & $25 \%$ & $25 \%$ & $8 \%$ & $25 \%$ & $58 \%$ & $83 \%$ \\
\hline $\begin{array}{l}\text { Impact } \\
\text { (hours) }\end{array}$ & 0.66 & 0.97 & 1.02 & 0.76 & 0.94 & 0.39 & 0.67 & 0.96 \\
\hline $\begin{array}{l}\text { Risk Severity } \\
\text { (hours) }\end{array}$ & $\mathbf{0 . 2 8}$ & $\mathbf{0 . 1 6}$ & $\mathbf{0 . 2 6}$ & $\mathbf{0 . 1 9}$ & $\mathbf{0 . 0 8}$ & $\mathbf{0 . 1 0}$ & $\mathbf{0 . 3 9}$ & $\mathbf{0 . 8 0}$ \\
\hline $\begin{array}{l}\text { Average Risk } \\
\text { Severity }\end{array}$ & \multicolumn{7}{|c|}{$\mathbf{0 . 2 8}$ hours } \\
\hline
\end{tabular}

Overall, Tables 3 and 4 suggest that currently, weather-related congestion has a risk severity of 0.69 hours, while system-related congestion has a risk severity of 0.28 hours. The tables therefore infer that weather-related congestion is of greater concern than system-related congestion. The tables indicate that the frequency and impact of both weather and system delays have fluctuated over the past eight years, which will likely continue in the future.

The results of the risk profile were subsequently illustrated in risk "heat-maps" by applying the coding system described earlier in the article. According to the risk "heatmap" of weather delays, as seen in Figure 10, weather-related port congestion was deemed a critical risk in 2011 and 2012.

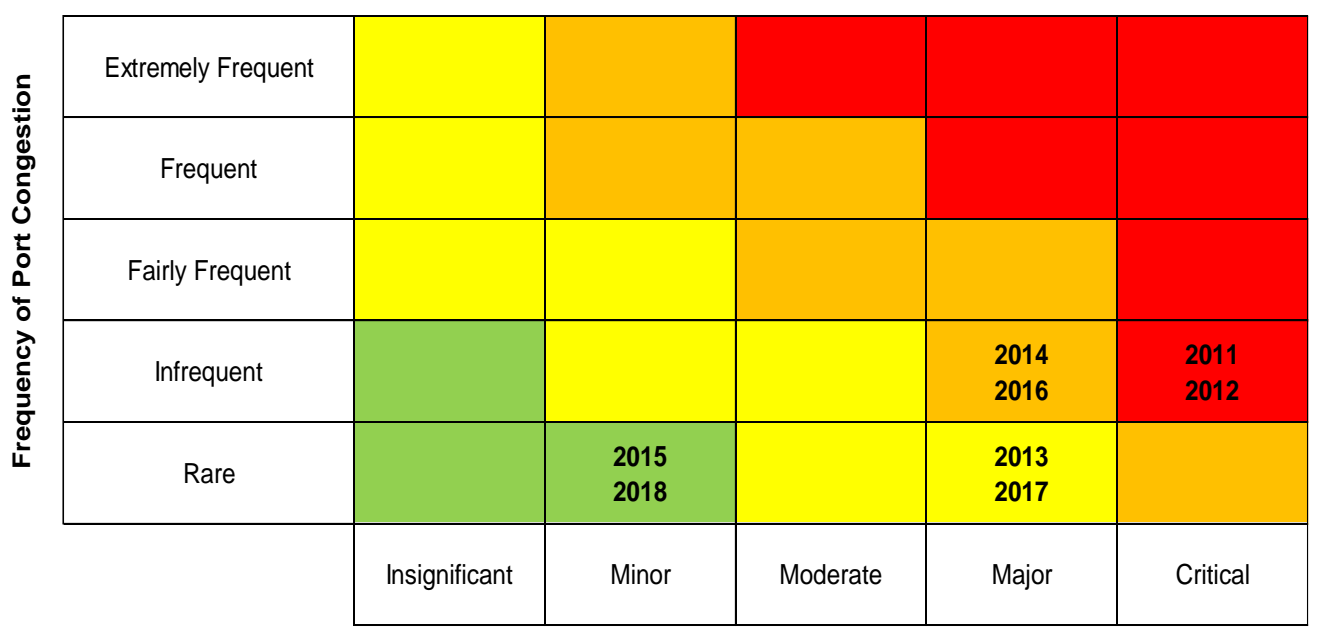

Time Impact of Port Congestion

Figure 10: Risk "heat-map" of weather-related port congestion 
This decreased to a moderate risk in 2013 before increasing to a major risk in 2014. The severity of the risk, however, decreased again to a minor risk in 2015, before increasing again to a major risk in 2016. Weather-related congestion then decreased to a moderate risk in 2017 and a minor risk in 2018. However, it is important to point out that CTCT was severely impacted by poor weather conditions during 2017 and 2018. This led to some customers opting to bypass the terminal, which resulted in lower volumes being handled by the CTCT (Transnet Port Terminals 2018). Feedback on the results of the research was provided to the shipping companies, TNPA and TPT and they agreed with the results.

With regard to system-related port congestion, seen in Figure 11, the risk to ocean carriers was deemed major from 2011 to 2012, and critical in 2013 with infrequent occurrences, but critical time impacts. This decreased to major risk in 2014 and 2015 before decreasing to a moderate risk in 2016. System delays increased to a major risk in 2017 and a critical risk in 2018 due to extremely frequent occurrences and critical time impacts. The main reason for the system-related port congestion during 2018 was due to multiple incidents of power outages, which resulted in system failures (Transnet Port Terminals 2019).

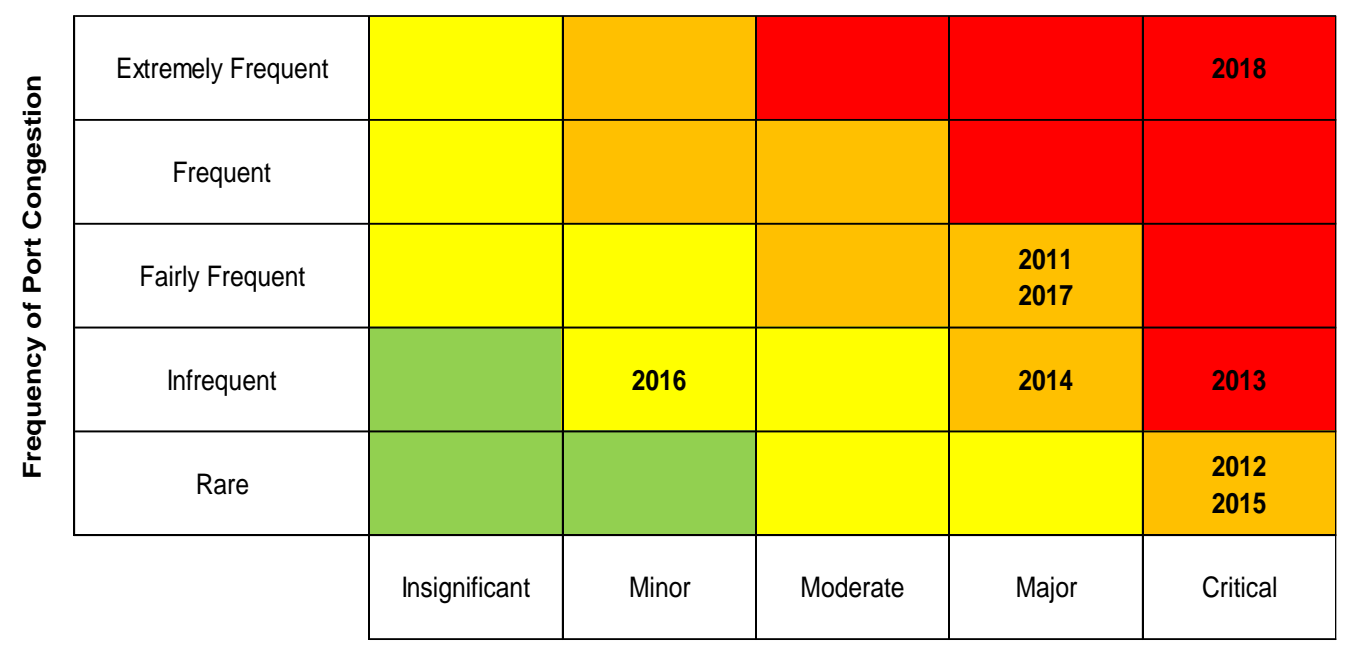

Time Impact of Port Congestion

Figure 11: Risk "heat-map" of system-related port congestion

Based on the "heat-map" ranking, two separate risk profiles were developed for weather-related congestion and system-related congestion. These risk profiles are illustrated in Table 5 and suggest that both weather- and system-related port congestions are currently considered major risks due to high time impacts and relatively high frequency of occurrences (2011-2018). 
Potgieter, Goedhals-Gerber and Havenga

Table 5: Risk profiles of current and future port congestion

\begin{tabular}{|c|c|}
\hline Risk Profile & Risk Rating \\
\hline Current Weather-related Port Congestion & Major Risk \\
\hline Current System-related Port Congestion & Major Risk \\
\hline
\end{tabular}

\section{Discussion}

The findings of this study indicate that while weather delays exhibited a slight downward trend, system delays exhibited a slight upward trend between 2011 and 2018. These two trend lines, however, do not suggest that delays experienced due to weather conditions are decreasing, or that delays due to system-related challenges are on the rise. The trends more likely indicate normal fluctuations due to the unpredictable nature of weather conditions, thus resulting in unpredictable occurrences and impact. In addition, the system delays are linked to the constant maintenance and upgrading done to the current TOS system as well as multiple incidents of power outages, which resulted in system failures (Transnet Port Terminals 2019).

Furthermore, findings indicate that the summer season experiences higher occurrences of more severe port congestion than the winter season. This is likely due to high wind speeds produced by the "Cape Doctor" (the local name given to these winds), which causes equipment shutdowns and prevents vessels from entering the port safely. This trend is likely to be found in future results due to the position of the port and the nature of weather conditions in Cape Town.

Information collected through interviews conducted for this research suggests conditions within the Port of Cape Town will likely change in the future. These conditions will likely change over the long term and include:

- Changes in weather conditions due to climate change with regard to rainfall, wind patterns and temperature changes.

- Increases in the number of vessels moving through the port due to increases in import/exports and passenger cruises.

- Potential datedness of the current TOS system requiring upgrades and maintenance.

- The potential implementation of the truck ban, resulting in a higher number of trucks entering/exiting the port in a given time period.

- $\quad$ The potential use of the BELCON terminal as an inland port.

- $\quad$ Future expansion plans to the container terminal and the construction of a passenger terminal in the Duncan Dock.

- $\quad$ Changes to the infrastructure of the City of Cape Town, which will further limit access to the port. 
The risk profiles developed of weather delays and system delays indicate that currently both weather- and system-related port congestions are ranked as major risks. Weather conditions will likely fluctuate in the future, resulting in fluctuating congestion. The likelihood of the current TOS system being replaced or upgraded is relatively high. In addition, the current likelihood of power outages is also relatively high. Both issues suggest that the risk rating of system-related congestion will likely change in the future.

\section{Recommendations}

With regard to the assumption that weather delays will likely remain a major risk due to the unpredictable nature of weather conditions, and the likelihood of port conditions changing over time, certain recommendations can be made. Due to the unpredictable nature of weather conditions the frequency of occurrences cannot be managed, however, the impact can be managed through improvements in equipment and in terminal procedures and processes. A possible solution to weather-related port congestion would entail either the upgrading of terminal equipment to handle higher wind speeds, or the reconfiguration of and/or expansion of the terminal stacks to allow for faster movement of containers between the stacks and the vessels. This would, however, require further research as it would require extensive financial investments.

A second recommendation includes improving coordination within terminal operations, which could decrease the impact of time delays. Improved operations could result in faster, more accurate movement of containers onto and off vessels, which could decrease the length of time spent in port.

Lang and Veenstra (2010) identified that container terminals and shipping lines around the world could benefit from better coordination. Terminal operators that manage congestion by improved levels of coordination rather than by facility investment have the added benefit of flexibility. Improved coordination allows terminal operators to operate their facilities at a higher level of utilisation (for a given service level) (Lang and Veenstra 2010).

Furthermore, expert training of terminal equipment operators could allow for longer productive periods, as operators would be skilled in knowing when to push for a deadline, and when to halt operations for safety reasons. This is specific to the operation of equipment under high wind speeds and thick fog.

With regard to the risk profiles of port congestion, it is recommended that action be taken now, before the risk escalates further. This can be done through further research into port congestion within the CTCT and the Port of Cape Town itself. Further research can be conducted to perform a cost analysis of port congestion in the Port of Cape Town to determine the cost implications of congestion. In addition, research can be conducted into landside congestion, including congestion inside the terminal (truck turnaround time) and outside the terminal (vehicle queuing). 


\section{Study limitations}

A potential cause for the high-risk ranking may be the coding system created and implemented to develop the risk profile of system delays. The coding system, which was developed using expert knowledge and perceptions of the severity of system delays, could be considered as stricter than the other coding systems created. The strictness of the coding system was created under the assumption that once a correct TOS system is implemented in a terminal; any errors should be minimal. Therefore, system delays were coded more strictly than weather delays. Regardless of the strictness of the coding system, the high risk ranking of system delays requires the consideration of TPT staff to reduce current delays and subsequently reduce the overall risk ranking of system delays within the CTCT.

\section{Conclusion}

The risk profiles infer that, should conditions within the terminal persist, both weatherand system-related port congestions should be considered major risks to operational efficiency as they result in major cost increases and time delays. Weather delays will likely remain a major risk due to the unpredictable nature of weather conditions, while system delays will likely fluctuate as upgrades and updates are implemented in the TOS and Eskom struggles to provide the required levels of electricity.

It is, however, imperative to note that conditions within the terminal are likely to change in the future, as demand for ports and the terminals within a port is a derived demand of trade, which will likely impact the severity and frequency of weather- and systemrelated port congestion (Begum 2003). Factors that contribute to port conditions include the productivity and availability of equipment, operations teams, tug-boats and stevedores; and adequate collaboration, coordination and communication between TNPA, TPT and shipping companies.

\section{References}

AFDB. 2010. “Chapter 2: Port Development in Africa.” Accessed March 4, 2015. http://www.afdb.org/fileadmin/uploads/afdb/Documents/Publications/African\%20Develop ment\%20Report\%202010_CH\%202.pdf.

Athanasatos, S., S. Michaelides, and M. Papadakis. 2014. "Identification of Weather Trends for Use as a Component of Risk Management for Port Operations." Natural Hazards 72 (1): 41-61. https://doi.org/10.1007/s11069-012-0491-z.

“Beaufort Wind Scale." 2015. Accessed August 20, 2015. http://www.marinewaypoints.com/marine/wind.shtml. 


\section{Potgieter, Goedhals-Gerber and Havenga}

Begum, H. 2003. "Impact of Port Efficiency and Productivity on the Economy of Bangladesh: A Case Study of Chittagong Port." Published Master's thesis: World Maritime University, Sweden. https://pdfs.semanticscholar.org/c8dd/b5038824bb301ba33bf30235c968098e0d4c.pdf.

Birkenstock, C. 2015. Personal Interview. 21 May. Transnet National Ports Authority House, Cape Town.

Brindley, C. 2004. Supply Chain Risk. England: Ashgate Publishing.

“Cape Town Weather Statistics.” 2014. Accessed November 19, 2015. http://winkfilms.tv/files/wink-weather-statistics.pdf.

Chadwin, M. L., J. A. Pope, and W. K. Talley. 1990. Ocean Container Transportation: An Operational Perspective. New York: Taylor \& Francis.

Choo, S., D. Klabjan, and D. Simchi-Levi. 2010. "Multiship Crane Sequencing with Yard Congestion Constraints.” Transportation Science 44 (1): 98-115. https://doi.org/10.1287/trsc.1090.0296.

City of Cape Town. 2014. "Storms and High or Gale Force Wind." Accessed August 20, 2015. https://www.capetown.gov.za/en/DRM/Pages/StormsandHighorGaleforceWind.aspx.

Davids, D. 2015. Personal Interview. 16 July. Transnet Port Terminals, Cape Town.

Davids, D. 2018. Personal Interview. 12 September. Transnet Port Terminals, Cape Town.

De Wet, C. J. 2014. “A Dry Port as an Expansion Option for the Cape Town Container Terminal.” Unpublished master's thesis. Stellenbosch: University of Stellenbosch.

Fan, L., W. W. Wilson, and B. Dahl. 2012. "Congestion, Port Expansion and Spatial Competition for US Container Ports.” Transportation Research Part E 48: 1121-1136. https://doi.org/10.1016/j.tre.2012.04.006.

Gidago, U. 2015. "Consequences of Port Congestion on Logistics and Supply Chain in African Ports.” Developing Country Studies 5 (6): 1-9.

Griffiths, M. 2007. “Creating Risk Profile Graphs.” Accessed October 5, 2015. http://leadinganswers.typepad.com/leading-answers/files/creating-risk-profile-graphs.pdf.

Janse van Rensburg, I. 1997. "The Economic Significance of the Port of Cape Town." Unpublished master's thesis. Stellenbosch: University of Stellenbosch.

Jeevana, J., H. Ghaderib, J. M. Bandarac, A. H. Saharuddina, and M.R.Othmana. 2015. "The Implications of the Growth of Port Throughput on the Port Capacity: The Case of Malaysian Major Container Seaports." International Journal of e-Navigation and Maritime Economy (3): 84-98. https://doi.org/10.1016/j.enavi.2015.12.008. 


\section{Potgieter, Goedhals-Gerber and Havenga}

Ke, G. Y., K. W. Li, and K. W. Hipel. 2012. "An Integrated Multiple Criteria Preference Ranking Approach to the Canadian West Coast Port Congestion Conflict." Expert Systems with Applications 39 (10): 9181-9190. https://doi.org/10.1016/j.eswa.2012.02.086.

Lang, N., and A. Veenstra. 2010.” A Quantitative Analysis of Container Vessel Arrival Planning Strategies.” OR Spectrum 32: 477-499. https://doi.org/10.1007/s00291-0090186-3.

Loh, H. S., and V. V. Thai. 2014. "Managing Port-related Supply Chain Disruptions: A Conceptual Paper.” The Asian Journal of Shipping and Logistics 30 (1): 097-116. https://doi.org/10.1016/j.ajsl.2014.04.005.

Lun, Y. H. V., K-H. Lai, and T. C. E. Cheng. 2010. Shipping and Logistics Management. London: Springer-Verlag. https://doi.org/10.1007/978-1-84882-997-8.

Marais, G. L. 2015. Personal Interview. 16 July. Safmarine/Maersk, Cape Town.

McEwan, R. 2015. Personal Interview. 14 August. MSC House, Cape Town.

Meersman, H., E. van de Voorde, and T. Vanelslander. 2012. "Port Congestion and Implications to Maritime Logistics." In Maritime Logistics Contemporary Issues, edited by D-W. Song and P. M. Panayides. Bingley: Emerald Group Publishing, 49-68. https://doi.org/10.1108/9781780523415-004.

Mentzer, J. T., T. P. Stank, and M. B. Myers. 2006. "Why Global Supply Chain Management?" Accessed April 30, 2017.

http://citeseerx.ist.psu.edu/viewdoc/download?doi=10.1.1.474.9932\&rep=rep1\&type=pdf.

Mokhtari, K., and J. Ren. 2014. "A Risk Management Methodology for Maritime Logistics and Supply Chain Applications." Ocean Systems Engineering 4 (2): 137-150. https://doi.org/10.12989/ose.2014.4.2.137.

Naude, J. 2016. “A Multi-Phase Model to Forecast Congestion at Brazilian Grain Ports : A Case Study at the Port of Paranagua." Stellenbosch University. Accessed October 9, 2019. https://scholar.sun.ac.za/handle/10019.1/98848.

Nel, D. 2015. Personal Interview and Statistical Assistance. Centre for Statistical Consultations, Stellenbosch.

Panayides, P. M., and D-W. Song. 2009. "Port Integration in Global Supply Chains: Measures and Implications for Maritime Logistics." International Journal of Logistics Research and Applications 12 (2): 133-145. https://doi.org/10.1080/13675560902749407.

Port of Cape Town. 2015. Accessed June 9, 2015. http://www.worldportsource.com/ports/review/ZAF_Port_of_Cape_Town_42.php.

Potgieter, L. 2016. "Risk Profile and Forecast of Port Congestion within the Cape Town Container Terminal.” Master's thesis, Stellenbosch: Stellenbosch University. 
Purdy, G. 2010. ISO 31000:2009: “Setting a New Standard for Risk Management." Society for Risk Analysis 30 (6): 881-886. https://doi.org/10.1111/j.1539-6924.2010.01442.x.

Richer, R. 2010. "Key Success Factors for the Implementation of an Inland Port in Cape Town.” Unpublished master's thesis. Stellenbosch: University of Stellenbosch.

Research Gate. 2019. "Methods of Data Collection.” Accessed March 2, 2019. https://www.researchgate.net/publication/325846997_METHODS_OF_DATA_COLLEC TION.

Rodrigue, J-P., and B. Slack. 2017. "Intermodal Transportation and Containerization." Accessed March 3, 2017.

https://people.hofstra.edu/geotrans/eng/ch3en/conc3en/ch3c6en.html.

Saunders, M., P. Lewis, and A. Thornhill. 2016. Research Methods for Business Students, 7th edition. Essex: Pearson Educational.

Stander, C. 2014. "The Handling of Fruit Reefer Containers in the Cape Town Container Terminal.” Master's thesis, Stellenbosch: Stellenbosch University.

Stanivuk, T., and T. Tokíc. 2012. "Croatian Operational Research Review.” Vol. 3. Split: Croatian Operational Research Society. Accessed October 9, 2019. https://doaj.org/article/957030e487994773a8f42f629565f14e.

Transnet Port Terminals. 2018. "Solutions Delivered.” Accessed September 3, 2019. https://www.transnet.net/InvestorRelations/AR2018/TPT.pdf.

Transnet Port Terminals. 2019. Accessed October 3, 2019. https://www.transnet.net/InvestorRelations/AR2019/Port\%20Terminals.pdf.

Tversky, A., and C. R. Fox. 1995. "Weighing Risk and Uncertainty.” Psychological Review 102 (2): 269-283. https://doi.org/10.1037/0033-295X.102.2.269.

Uusitalo, L., A. Lehikoinen, I. Hellec, and K. Myrberg. 2015. “An Overview of Methods to Evaluate Uncertainty of Deterministic Models in Decision Support.” Environmental Modelling and Software 63: 24-31. https://doi.org/10.1016/j.envsoft.2014.09.017.

Van Eeden, J. 2019. Personal Interview, Stellenbosch.

Veloqui, M., I. Turias, M. M. Cerban, M. J. Gonsalez, G. Buize, and J. Beltran. 2014. "Simulating the Landside Congestion in a Container Terminal: The Experience of the Port Of Naples (Italy).” Journal of Social and Behavioural Science 160: 615-624. https://doi.org/10.1016/j.sbspro.2014.12.175.

Young, J. 2014. Operational Risk Management, second edition. Pretoria: Van Schaik. 